\title{
Value Analysis Tool for Feasibility Studies of Biorefineries I ntegrated with Value Added Production
}

\author{
J Sadhukhan ${ }^{1 *}$, MA Mustafa ${ }^{1,2}$, N Misailidis², F Mateos-Salvador ${ }^{1,2}, \mathrm{C} \mathrm{Du}^{2}$ and GM \\ Campbell ${ }^{2}$
}

\begin{abstract}
${ }^{1}$ Centre for Process Integration, ${ }^{2}$ Satake Centre for Grain Process Engineering, School of Chemical Engineering \& Analytical Science, The University of Manchester

P.O. Box 88, Manchester, M60 1QD, UK
\end{abstract}

\begin{abstract}
A value analysis methodology (Sadhukhan et al, 2003 and 2004; Sadhukhan and Smith, 2007) has been presented for investigating into the economic feasibility of biorefineries. The methodology devises a mechanism for systematic design of industrial systems based on comprehensive assessment of value on processing and cost of production, hence marginal contributions from individual processing routes and products. The feasibility of extracting value added products such as arabinoxylans (AX) from wheat bran within a wheat biorefinery principally producing ethanol has been investigated. Site-wide integrated flowsheets have been created by which $A X$ can be extracted after recovering bran from wheat with ethanol production from the remaining wheat. Based on the most promising test case, value analysis shows that creating a market for $A X$ is feasible in terms of production costs if the $A X$ is coproduced with ethanol. A comprehensive value analysis that includes capital investment policies indicates that the required market price for $A X$ to breakeven against conventional biorefineries without value added production is a strong function of plant life and this may vary between 4-6 $\mathrm{f} / \mathrm{kg}$ for a plant life of 5-2 years respectively. Further it shows that if a market can be created for $A X$ as a food ingredient with a selling price of $6 \mathrm{f} / \mathrm{kg}$, the ethanol co-produced can be sold at $10 \%$ less than from a conventional biorefinery under current economic scenario.
\end{abstract}

Keywords: biorefinery, ethanol, arabinoxylan, cereals, value analysis, process integration

\footnotetext{
* Author/s to whom correspondence should be addressed: Jhuma.Sadhukhan@manchester.ac.uk Ph. +44 161 3064396; fax. +44 1612367439
} 


\section{Introduction}

Tackling the world energy crisis and global warming is among the top priorities nationally and internationally. Alternative energy sources such as renewable raw materials like cereals are therefore urgently sought to produce biorenewable fuels such as bioethanol in response to both diminishing world oil reserves and increasing environmental concerns over global climate change. Wheat is presented as the main cereal in the UK and EU. Production of bioethanol is increasing rapidly around the world (GAIN report: RP7029, 2007). It is recognised that in order to make bioethanol production economically competitive and commercially feasible, the ethanol must be produced as one of several co-products within a biorefinery. Currently Distillers Dried Grain with Solubles (DDGS) is the major co-product of bioethanol production, but this is a relatively unsophisticated and low value product which is likely to be lower in value even further as the amount of bioethanol production increases. Broadly speaking, it is the bran fraction of wheat that is problematic for non-food processing, in terms of representing a large fraction of the raw material but ending up in a low value product such as DDGS.

Starch is fermented to ethanol, protein may be recovered, but bran can currently only be burned or sold as animal feed. Adding value to the bran fraction of wheat is necessary in order to enhance the economics of wheat-based biorefineries. Extraction of components of the bran appears to be the most promising route towards producing added-value products.

Products from biorefineries must compete with oil-derived products. At the same time, biorefineries must be designed using the precedence of oil refineries and must adopt and benefit from concepts developed in oil refining that have made it the efficient operation it is today. The oil refining model of extensive fractionation in order to extract value from every last drop of the barrel of oil must be adapted for cereal biorefineries. In order to produce products that can compete with oil-derived products, cereal biorefineries must adopt the pattern of extensive fractionation and value addition within highly integrated processes. Bioethanol production is ushering in the new world of cereal biorefineries - the need for bioethanol is the driver for developments in this area, but these developments will lead to other products from cereals, including platform chemicals and plastics (Koutinas et al, 2006, Campbell et 
al, 2006). For its own sake and for the sake of the wider range of sustainable products that will follow, there is urgency for adopting the process integration approaches as oil refineries and chemical industries for a competitive economic operation.

In the case of bioethanol, arabinoxylan (AX) appears to be a suitable candidate for coproduction. $A X$ is present in wheat bran at high levels, and can be extracted in a process that uses large quantities of ethanol. This latter point immediately suggests a scope for efficient and economical recovery of AX within a process principally producing bioethanol. Extraction of $\mathrm{AX}$ would also slightly reduce production of DDGS which, in the face of greatly increased bioethanol production capacity, would be increasingly difficult to find market.

AX has several important functional properties that promise valuable applications in both the food and the non-food industries. These properties include viscosity enhancement and gel formation, and possibly foam stabilization and prebiotic activity (Bergmans et al, 1996 and 1999; Courtin and Delcour, 2002; Grootaert et al, 2007). Applications include possible use in bakery and dairy products, incorporation into packaging films and for pharmaceutical products including wound dressings (Courtin and Delcour, 2002; Miraftab et al, 2003; Peroval et al, 2004; Grootaert et al, 2007). In addition, the $A X$ extraction process uses large quantities of ethanol to wash the bran and to precipitate the $A X$, which immediately offers scope for cost savings through process integration. However, $A X$ is not currently available in large quantities commercially, and some of these applications are not yet demonstrated, particularly for wheat-derived AX. Creation of a commercial source of $A X$ through co-production with ethanol would need concurrent creation of suitable markets for this novel product, which is not considered in this work. However, before further research on the functionality and possible end-uses of $A X$ can be justified, it needs to be established whether in reality, under plausible scenarios, AX can be produced at a cost sufficiently low that the creation of a market for this product will be feasible. This research investigates into the design and integration of process flowsheets for producing $A X$ in the context of wheat bioethanol plant.

The process integration tool developed for designing such integrated biorefineries is based on the value analysis methodology derived by Sadhukhan et al (2003 and 2004) and Sadhukhan and Smith (2007). It builds from the graph theory by representing a processing route as a graph that consists of arcs (streams) and nodes 
(processes), interconnected to form paths and trees (Mah, 1983). First, the economic margins of individual streams in such processing paths or trees are evaluated from the predicted values of their value on processing and cost of production. Next, the economic margins are established for the processing paths and trees from the marginal contributions of streams belonging to processing paths / trees. These are then correlated to the overall margin of an entire network. An overall integration strategy is developed so as to capture the impact of variable operating conditions and complex network connections in the detailed differential value analysis of systems.

This paper presents the value analysis methodology in section 2 . Section 3 demonstrates the value analysis of a conventional wheat based bioethanol production flowsheet without any value added production. Section 4 describes the identification and value analysis of process flowsheets by which bran can be recovered from wheat for the purposes of $A X$ extraction. The $A X$ extraction section is integrated with the starch fermentation section producing ethanol. The flowsheets developed in the current work to integrate starch and barn extraction activities are presented. Capital cost analysis is then implemented in the value analysis of the integrated process flowsheets using the methodology proposed by Sadhukhan (2005) in section 5. Finally the work has been summarised in section 6 .

\section{Value analysis of process networks}

Mah (1983) has demonstrated one to one correspondence between a process network and a directed graph. Sadhukhan et al (2003 and 2004) have showed the foundation of process networks at basic tree and path levels (elements) comprising streams and process units, such that the total marginal contributions of the basic elements in a process network equate to the margin of the overall network (Figure 1). At first, individual streams in basic elements in a process network are evaluated in terms of their value on processing (VOP) and cost of production (COP) based on given network configuration, internal and external (market) constraints. The difference between the two (VOP - COP) of a stream provides the marginal contribution from the stream. Next, a complete stream in each basic element is identified, defined later, in order to equate its marginal contribution to that of the element in which it belongs to. Thereafter, the marginal correlations are derived between basic elements (paths and 
trees) and an overall network, given by the summation of the economic margins of individual basic elements in the network.

The derivation of Value on Processing (VOP) and Cost of Production (COP) of streams is illustrated using an example of a single process unit with an inlet and outlet streams (Sadhukhan, 2002). The economic margin of this process unit $(\Delta)$ is given by the difference between the spot on price of the product (spot on price of the product $x$ flowrate of the product: $(P)_{M P} \times \mathrm{m}^{\mathrm{P}}$ ) and the cost of the feed (market price of the feed $\times$ flowrate of the feed: $(F)_{M P} \times \mathrm{m}^{\mathrm{F}}$ ) and the total operating cost $(\mathrm{O})$ of the unit (unit operating cost multiplied by the throughput through the unit). This margin is associated with the COP of the product $\left((P)_{C O P}\right)(E q .1)$ and the VOP of the feed $\left((F)_{\text {Vop }}\right)($ Eq. 2).

$$
\begin{aligned}
\Delta & =(P)_{M P} \times m^{P}-\left((F)_{M P} \times m^{F}+O\right) \\
& =(P)_{M P} \times m^{P}-\left((P)_{M P} \times m^{P}\right)_{\Delta=0}=\left\{(P)_{M P}-(P)_{C O P}\right\} \times m^{P} \\
= & \left((F)_{M P} \times m^{F}\right)_{\Delta=0}-(F)_{M P} \times m^{F}=\left\{(F)_{V O P}-(F)_{M P}\right\} \times m^{F}
\end{aligned}
$$

The evaluation of COP of streams starts from known market price of feedstocks and proceeds in the forward direction until end products in a directed network graph. The VOP evaluation proceeds in the backward direction for a process network to evaluate one after another stream from the end products with known spot on price to the feedstock. The difference between VOP and COP of a stream provides its economic margin or marginal contribution. It can be noted that the COP of a feedstock to a process flowsheet is nothing but its market price and similarly VOP of an end product is its spot on price.

The various stages for value analysis at individual stream, element and process network levels are summarised as follows.

- The marginal correlations in Eqs. 3-5 are used to predict VOP and COP and thereby economic margins of streams respectively. The cost of production per unit flowrate (COP) of products (intermediate stream $\mathrm{F}_{\mathrm{e}-\mathrm{i}-\mathrm{e}^{\prime}}$ produced from element e-i to element $e^{\prime}$ and end product $P_{e-i, q}$ ) from a unit $i$ is equal to the summation of the cost of production of the feedstock $F_{e-i}$ to the unit and the unit operating cost $\left(\widehat{o}_{\mathrm{i}}\right)$ of the unit (Eq. 3). The unit operating cost of a unit is a function of the feedstock flow and properties and product yields. The value on processing expressed by VOP of 
feedstocks $F_{e-i}$ from element e to a unit $i$ is predicted from the summation of the value on processing of intermediate products $\mathrm{F}_{\mathrm{e}-\mathrm{i}-\mathrm{e}^{\prime}}$ to element $\mathrm{e}^{\prime}$ and spot on prices (indicated by MP) of end products $\mathrm{P}_{\mathrm{e}-\mathrm{i}, \mathrm{q}}$, subtracted by the unit operating cost $\left(\widehat{o}_{\mathrm{i}}\right)$ of the unit (Eq. 4). $m_{e-i-e^{\prime}}^{F}, m_{e-i, q}^{P}$ and $m_{e-i}^{F}$ represent the flowrates of intermediate and end products and feedstock of unit i respectively. As can be noted, the COP of streams is ultimately connected to the market prices of feedstocks to a processing route / plant, while VOP is linked to the spot on prices of end products from the processing route / plant. Economic margin from a stream $F_{e-i}$ given by the difference between its VOP and COP is contributed by the margins of process units involved in its production (upstream units $u \in U S \_U N I T(i)$ ) and processing (downstream units i and $d \in D S_{-} U N I T(i)$ ) (Eq. 5).

$$
\begin{aligned}
& \left(F_{e-i-e^{\prime}}\right)_{C O P}=\left(P_{e-i, q}\right)_{C O P}=\left(F_{e-i}\right)_{C O P}+\widehat{o}_{i} \\
& \forall i \in U N I T, e \in E U(i), e^{\prime} \in E D(i), q \in N P(i)
\end{aligned}
$$

Cost of Production (COP) of a stream is the cost of the feedstock plus the operating costs of upstream units that have contributed to the production of the stream.

$$
\begin{aligned}
& \left.\left(\mathrm{F}_{\mathrm{e}-\mathrm{i}}\right)_{\mathrm{VOP}}=\left[\sum_{e^{\prime} \in E D(i)}\left(\mathrm{F}_{\mathrm{e}-\mathrm{i}-\mathrm{e}^{\prime}}\right) \mathrm{VOP} \times m_{e-i-e^{\prime}}^{F}+\sum_{p \in N P(i)}\left(\mathrm{P}_{\mathrm{e}-\mathrm{i}, \mathrm{q}}\right)_{\mathrm{MP}} \times m_{e-i, q}^{P}-\widehat{O}_{\mathrm{i}} \times \sum_{e \in E U(i)} m_{e-i}^{F}\right\}\right] \\
& / \sum_{e \in E U(i)} m_{e-i}^{F} \quad \forall \mathrm{i} \in \mathrm{UNIT}, \mathrm{e} \in \mathrm{EU}(\mathrm{i})
\end{aligned}
$$

Value on Processing (VOP) of a stream is the spot on price of its end products subtracted by the operating costs of downstream units processing the stream.

$$
\begin{aligned}
& \sum_{u \in U S \_U N I T(i)} \Delta_{\mathrm{u}}\left(\mathrm{F}_{\mathrm{e}-\mathrm{i}}\right)+\sum_{d \in D S \_U N I T(i)} \Delta_{\mathrm{d}}\left(\mathrm{F}_{\mathrm{e}-\mathrm{i}}\right)+\Delta_{\mathrm{i}}\left(\mathrm{F}_{\mathrm{e}-\mathrm{i}}\right)=\left\{\left(\mathrm{F}_{\mathrm{e}-\mathrm{i}}\right)_{\mathrm{VOP}}-\left(\mathrm{F}_{\mathrm{e}-\mathrm{i}}\right)_{\mathrm{COP}}\right\} \times m_{e-i}^{F} \\
& \forall \mathrm{i} \in \mathrm{UNIT}, \mathrm{e} \in \mathrm{EU}(\mathrm{i})
\end{aligned}
$$

- A complete stream in an element for which there is no component stream available in any other elements and the flowrate of the stream is equal to the maximum flowrate through the element, is identified and marginal values are predicted using 
Eqs. 3-5. A complete stream should satisfy 2 criteria: a) it must appear only once in one of the basic elements (paths or trees) in a process network and b) its flowrate is equal to the maximum flowrate through the element in which it belong to. In the network example in Figure 1, although the streams F1 and F1-4 are meeting the second criterion, they are not the complete streams as they have appeared in more than one element, $\mathrm{F} 1$ in all the four elements and F1-4 in the first two paths respectively. In the trees 1-4-6-3 and 1-5-2-3, although the streams F1-4-6-3 and F1-5-2, F1-5-2-3 respectively do not appear in any other path, they are not the complete streams as their individual flowrates are not equal to the maximum flowrate through these trees. Thus, the complete streams in the first path are F1-2, F1-2-3 and P1-2-3, in the second path are F1-4-2, F1-4-2-3 and P1-4-2-3, in the third tree is F1-4-6 and in the fourth tree is F1-5 in Figure 2.

- The economic margin of any such complete stream in an element provides the margin of the element in a network. Once the economic margins of the basic elements in a process network (e.g. Figure 1) are obtained, their summation provides the margin of the overall system.

- Later, Eqs. 3-4 were modified by Sadhukhan (2005) and Sadhukhan and Smith (2007) to incorporate the capital investments of units associated with a stream in the form of tolling fees.

The tolling fee associated with a stream to a process unit is calculated using discounted cash flow economic model in terms of capital cost of the process unit per unit flowrate of the stream fed, internal rate of return, annual charge and the number of years until the net present value is zero. The latter three input variables are dependent on the overall system economics. The correlations so derived can capture the variations in internal capital and operating costs as well as in external inputs (market prices, annual charges etc). Tolling fees calculations are detailed elsewhere (Sadhukhan, 2005) and an illustration from Sadhukhan (2005) is presented here.

\section{Figure 1}

The value analysis tool also helps in planning, scheduling and day-to-day decision making on selling and purchasing strategies for streams (Sadhukhan et al, 2004). There are 3! arrangements possible among three values of a stream, VOP, COP and market price (VOP $>$ COP $>$ market price; VOP $>$ market price $>$ COP; market price $>$ 
VOP > COP; and so on) based on which various market integration strategies can be developed (Sadhukhan et al, 2004).

An ideal case is when the spot on price of a stream is in between its VOP and COP. The margins incurred from both production and processing of the stream are positive (Eqs. 3-4) and so is the overall economic margin of the stream. Thus, a necessary and sufficient condition for a stream to be non-profitable is when its COP is more than its VOP in a given network.

In the value analysis methodology streams are evaluated sequentially in the forward or backward directions in a directed process network in order to predict COP and VOP of streams respectively. This can pose a problem in predicting VOP and COP, where there exist loops such as recycle streams, which are common in process flowsheets. Sadhukhan et al (2003) has presented a methodology for the value analysis of loops / recycle streams that deals with the tearing of recycle streams and evaluation of COP and VOP of such streams separately using their production and processing elements respectively. The calculation procedure for recycles streams is detailed with examples elsewhere (Sadhukhan et al, 2003).

\section{Value analysis of a wheat based conventional bioethanol flowsheet}

Following the procedure discussed in section 2, a value analysis framework for various bioethanol flowsheets proposed has been developed in EXCEL environment. These are used in the EXCEL based value analysis framework for predicting operating costs of various processes. The capital cost analysis is discussed later. Figure 2 depicts the value analysis and mass balance of a conventional bioethanol plant flowsheet with major process units. The conventional process yields nearly equal amount of ethanol, DDGS and $\mathrm{CO}_{2}, 34,25$ and $30 \%$ respectively, with the rest as waste streams. The governing reaction is as follows: $\mathrm{C}_{6} \mathrm{H}_{12} \mathrm{O}_{6}=2 \mathrm{C}_{2} \mathrm{H}_{5} \mathrm{OH}+2 \mathrm{CO}_{2}$. The utility consumptions and recovery of various process units in Figure 2 are provided in Tables A1 and A2 respectively in Appendix A. Table A3 summarises the price information for the various raw materials, products and utilities. Tables A4-A5 provide the wheat and bran compositions respectively. The utility consumptions and yields of processes, spot on prices and compositions as provided in Appendix A are established from Smith et al 
(2006), Sinnott (2003) and in consultation with Home-Grown Cereals Authority, UK. Appendix A also presents a brief discussion on process unit selection and modelling aspects of conventional wheat bioethanol plant in Appendix A. It can be noted that this research (Home-Grown Cereals Authority of the UK funded, RD-2005-3186, 2005) has been undertaken in the context of the UK economics and therefore the economic parameters are provided in pound sterling.

\section{Figure 2}

Figure 3

Table 1

Table 2

Using the value analysis methodology discussed in section 2, the overall economic margin for the conventional flowsheet in Figure 2 is calculated as $99.67 \mathrm{f} / \mathrm{t}$ of wheat processed. The basis of calculation is a wheat-based biorefinery processing $340,000 \mathrm{t}$ of wheat per annum with 330 operating days per year producing $99.6 \%$ pure ethanol. The economic margin from a typical bioethanol flowsheet in Figure 2 can be predicted from the marginal value contributed by wheat or from the net profit from the end streams, ethanol, DDGS, $\mathrm{CO}_{2}$ and the waste streams in Figures 2-3a respectively. An illustration of the calculations of COP and VOP is provided in Table 1. Figure 3a depicts the marginal contributions from individual end streams. The $y$-axis presents the various COP/VOP values of the products whereas $x$-axis corresponds to the flowrates of products (known as stream economic profile by Sadhukhan et al, 2003 and 2004). The net positive area presented above the cost of production line and between the values on processing of the end streams equates to the economic margin of the overall flowsheet in Figure 2.

The total operating cost of the facility is $f 40.9$ million which corresponds to $120.19 \mathrm{f} / \mathrm{t}$ of wheat processed with $90 \%$ contribution from raw materials due to the price of wheat in the UK and only $10 \%$ for utilities. Our results were validated against Batchelor et al (1994), who similarly found bioethanol production to be highly sensitive to wheat price and moderately sensitive to other prices. Table 2 comprises the percentage distribution of various cost components associated with the ethanol production in Figure 2. Concerning the utilities, the highest costs are due to the consumption of steam, electricity and natural gas. This is also reflected in Table 2 with the highest costs of operation due to the ethanol recovery and liquefaction stages, 
where there is a high consumption of steam. The capital cost analysis (Sadhukhan, 2005) is presented in section 5.

\section{Value analysis of flow sheets for arabinoxylan extraction}

Wheat-based biorefineries are in principle capable of producing a wide range of products, including biofuels, platform chemicals and biodegradable plastics through starch exploitation. However, to boost the biorefinery economics, exploitation of bran fraction is also required. The most promising product from bran seems to be arabinoxylan. A number of procedures are available for the extraction of $A X$ in literature, Bergmans et al (1996), Bataillon et al (1998), Maes and Delcour (2001) and Weightman et al (2002). The current work is aimed at producing AX suitable for food use, which can be extracted from wheat bran using alkaline hydrogen peroxide, with ethanol used for bran washing and $A X$ precipitation, and the extract purified with enzymatic treatments. Thus, the alkaline hydrogen peroxide extraction and ethanol precipitation procedure proposed by Hollmann and Lindhauer (2005) has been adopted in the current work based on the following considerations:

1) It employs inherently low toxicity chemicals, whereas some other procedures use materials inappropriate for a product intended for food use, such as barium hydroxide for the AX extraction instead of alkaline hydrogen peroxide;

2) It allows direct bioethanol integration;

3) It describes a pilot-scale procedure whereas others are at a lab-scale;

4) It provides a relatively high recovery of AX of approximately $50 \%$.

Hydrogen peroxide under alkaline conditions operates by oxidising the lignin in the bran, thereby breaking linkages with the polysaccharides (i.e. the $A X$ ) and facilitating the latter's extraction (Maes and Delcour, 2001). Maes and Delcour (2001) and Hollmann and Lindhauer (2005) used sodium hydroxide to maintain alkaline conditions; however, $\mathrm{NaOH}$ absorbs $\mathrm{CO}_{2}$ from the air to form carbonates, such that the $\mathrm{pH}$ reduces over time. Alternative sources of alkali such as potassium or calcium hydroxide might prove less problematic (Weightman, 2002).

The AX extraction procedure was modified to be suitable for industrial scale operation as follows. 
1) Removing the intermediate drying step that was evidently employed for convenience of laboratory operation, but would not be employed at industrial scale;

2) Using rotary drum dryers instead of circulating air dryers, to allow ethanol recovery;

3) Combining the decantation and centrifugation steps, to simplify the flowsheet;

4) Omitting the acetone washing, dialysis and freeze drying steps, since they are suitable for laboratory work but generally inappropriate at the industrial scale.

Figure 4 presents the $70 \%$ purity AX extraction flowsheet by Hollmann and Lindhauer (2005) with the modifications indicated above. Bran is treated in Treatment 1 to remove low molecular weight contaminations and to inactivate arabinoxylandegrading enzymes. This is achieved by suspending bran in $70 \%$ ethanol and heating to $80^{\circ} \mathrm{C}$ for $4 \mathrm{~h}$ with stirring. The resulting slurry is then sieved and washed with $70 \%$ ethanol. A second treatment step (Treatment 2) is applied to remove waterextractable arabinoxylan by suspending the purified bran in water for $2 \mathrm{~h}$ at $40^{\circ} \mathrm{C}$. Once more, the product goes through a sieving and washing step, however this time with cold water. The product from the previous step is added to Treatment 3 which achieves the $A X$ extraction through addition of hydrogen peroxide, $\mathrm{pH}$ adjustment to 11 , temperature adjustment, and the addition of protein-degrading enzyme (alcalase). This is followed by sieving and washing with water. The collected filtrate is concentrated to one-fifth of its initial volume using an ultrafiltration step. Ethanol precipitation is undertaken using $96 \%$ ethanol to bring the retentate to a final concentration to $65 \%$. The precipitated material is allowed to settle out at $4{ }^{\circ} \mathrm{C}$. Centrifugation, washing (with $96 \%$ ethanol), and drying then follow. This proposed procedure is capable of producing a $70 \%$ purity product.

\section{Figure 4}

Figure 5

To produce a higher purity product of $80 \%, \beta$-glucans are removed through an additional purification operation in which an enzyme (lichenase) is added, as shown in Figure 5. The additional operation: Treatment 4, includes the following steps: addition of enzymes, temperature adjustment, $\mathrm{pH}$ adjustment, and heat inactivation of the enzymes. Both the flowsheets in Figures 4-5 are used to integrate with the starch processing flowsheet in Figure 2. 
Figures 6-7 show the integrated starch processing (Figure 2) and $A X$ extraction (Figures 4-5) flowsheets with $70 \%$ and $80 \%$ purity of AX product respectively. Various types of bran can be used for arabinoxylan extraction. Bran can be collected using debranner, roller mill or by sieve followed by hammer mill. The latter is the cheapest but the least efficient option. Alternatively, bran can be purchased from an external source, e.g. from a flour miller, if demand for extraction product goes up.

The following considerations play a major role in deciding the utilization of bran fraction in the integrated flowsheet designs.

1) It clearly presents that sending bran to DDGS has no economic benefit and hence sending bran to DDGS is not recommended.

2) It should fully integrate bioethanol within the biorefinery (Figure B1 in Appendix B).

3) It should recover any starch remaining in the bran by washing the bran with water prior to extraction and sending it back to the liquefaction stage.

4) Furthermore, it can be safely assumed that it is much better to recover AX using the debranning option instead of the roller milling option due to the following reasons: experimental results at a Manchester lab show that $A X$ seems to be concentrated on the outer layers of wheat which can be extracted using a debranner; and the utility consumption (electricity) in debranning is less than in roller milling for which several milling and sifting stages are required to give a reasonably clean bran (Mustafa et al, 2007).

\section{Figure 6}

Figure 7

Figure 8

The flowsheets in Figures 6-7 retain the flexibility of employing either debranning or roller milling or both to obtain the bran for extraction. It does not imply that all bran initially associated with wheat needs to be recovered for AX extraction - only that the bran recovered needs to be processed for $A X$ production rather than the DDGS production. The amount of bran to be extracted from wheat is dependent on the market demand of $A X$.

Appendix B provides raw material and utility requirements and ethanol reuse options within an integrated ethanol and $A X$ flowsheet superstructure, as the basis for value analysis of flowsheets $6-7$. The results indicate that the minimum market value for $A X$ 
product with $70 \%$ and $80 \%$ purity is $1500 \mathrm{f} / \mathrm{t}$ and $2355 \mathrm{f} / \mathrm{t}$ respectively, based on break even point that gives the same economic margin as the conventional bioethanol flowsheet in Figure 2. Above these market values of $A X$, its production starts to become economically more favorable than a conventional bioethanol plant. Figure 8 demonstrates the sensitivity of the overall economic margin to AX price. Further investigation into the production of $80 \% \mathrm{AX}$ product reveals that the total annual operating cost of the plant in Figure 7 is $£ 45.4$ million, which corresponds to 133.43 $\mathrm{f} / \mathrm{t}$ of wheat processed. This represents an increase by $11 \%$ in the total operating cost relative to the base case (Figure 2). It is clear that the economics are much more sensitive to ethanol price than to the price of $A X$, due to the much higher yield of ethanol compared to AX. Hence, AX production will appear to be more promising with the increase in its market demand.

Figure $3 \mathrm{~b}$ shows the marginal contributions from individual products in the integrated flowsheet in Figure 7 with $80 \%$ purity AX co-product. All waste streams are presented as a combined waste stream which is mainly composed of water. The flowrate of the combined waste stream is above $500 \mathrm{kt} / \mathrm{y}$ however, only a small portion is shown in order to focus on the value analysis of the key products. For marginal contributions from individual products the area bounded between VOP-COP and flowrate of individual products is predicted. Figure $3 \mathrm{~b}$ presents the market value of $2355 \mathrm{f} / \mathrm{t}$ of 80\% purity $A X$ required to provide a total economic margin similar to the base case. The amount of $\mathrm{AX}$ produced is small $4 \mathrm{kt} / \mathrm{y}$ compared to ethanol production, $113 \mathrm{kt} / \mathrm{y}$. Selling any product at a price that exceeds its COP results in a profitable stream.

\section{Capital cost analysis}

The direct fixed capital (DFC) of the conventional flowsheet (Figure 2) and the integrated flowsheet with $\mathrm{AX}$ co-production (Figure 7) is presented in Table 3 . The calculation basis (Kwiatkowski et al, 2006) is detailed elsewhere (Mustafa et al, 2007). The estimated DFC for an AX co-producing flowsheet with debranner is slightly more than without the bran extraction option.

Further, Discounted cash flow calculations (DCF) by Sadhukhan (2005) were carried out to include the annualised capital charge in the form of tolling fees into the value analysis of the products. The DCF in this case is adopted from Sadhukhan (2005) as follows. For a given Internal Rate of Return of $12 \%$, a construction period of 3.25 
years before plant start up ( $0^{\text {th }}$ year corresponds to the plant start up), a plant life of 5 years after start up and a construction policy of $10 \%, 40 \%, 40 \%$ and $10 \%$ investments of total capital in the years $=-3,-2,-1,0$ respectively, the simple cash flow and discounted cash flow in various years calculated are given in Table 4. Bioethanol plants are either adjunct facilities or stand-alone plants. Adjunct facilities are appended to existing sugar mills and need at least 18 months to build, while a standalone plant usually takes 24-30 months to construct (GAIN report: RP7029, 2007). For a complex bioethanol plant integrated with $\mathrm{AX}$ co-production and ethanol recycling, a completion period of 36-40 months is expected including commissioning, similar to integrated bioenergy facilities (Hamelinck et al, 2005). The net present value (NPV) of a plant is calculated by the cumulative cash flows, simple or discounted. Hence the simple and actual payback time when NPV is zero, is 3.5 and 5 years respectively from the year of plant start up or 6.75 and 8.25 years respectively in total as shown in Table 4. An annualised capital charge of $28 \%$ is predicted that satisfies the above conditions discussed. This percentage annualised capital charge multiplied with DFC for a plant (e.g. Table 3) provides the tolling fees (in $f / y$ ) of the plant. Thus the tolling fees per unit flowrate (in $f / t$ ) of a stream can be calculated for its production as well as processing routes and added to its COP (Eq. 3) or subtracted from its VOP (Eq. 4) respectively for incorporating the effect of capital cost in the value analysis of the stream, demonstrated by Sadhukhan (2005).

A sensitivity analysis has been carried out on the annualised capital charge with respect to plant life for the same IRR, construction policy and period stated above. Annualised capital charge is strongly dependent on the payback time when NPV is zero. As one intends to pay off loan quicker (reduction in payback time), annualised capital charge increases exponentially. For a plant life of 3 and 2 years from plant start up, the annualised capital charge predicted is $42 \%$ and $59 \%$ respectively.

Applying the above analysis to the integrated biorefinery flowsheet with $80 \% \mathrm{AX}$ production in flowsheet 7, it is thus clear that as the plant life reduces from 5 to 2 years, AX market value should go up in order to pay off increasing annualised capital charge or tolling fees. It has been found that the required $A X$ market price varies between $4 \mathrm{f} / \mathrm{kg}$ to $6 \mathrm{f} / \mathrm{kg}$ as the payback time reduces, in order to breakeven with the conventional biorefinery flowsheet in Figure 2 . Hence estimated market price of $A X$ is a strong function of CAPEX. This certainly invokes further research scope for 
investigating into material and energy integration and optimisation of biorefinery flowsheets with integrated AX co-production.

Table 5 presents a comprehensive comparison of economics with the consideration of capital cost (CAPEX) between conventional and integrated AX co-production flowsheets in Figures 2 and 7 respectively for various annualised capital charges predicted above. Three different scenarios have been considered: Plant life (from plant start up) of 5,3 and 2 years and corresponding predicted annualised capital charge of $28 \%, 42 \%$ and $59 \%$ respectively. The economic performance of the conventional flowsheet is better than the integrated $A X$ co-production flowsheet by 23.5, 29.74 and $37.62 \mathrm{f} / \mathrm{t}$ of wheat, for annualised capital charge of $0.28,0.42$ and 0.59 respectively, when the capital cost (CAPEX) is included in the value analysis carried out earlier in Figure 3. This is equivalent to 1997.86, 2527.8 and $3197.66 \mathrm{f} / \mathrm{t}$ of difference in economic margin based on $A X$ production route alone, respectively. In order to retain the same economic margin between the integrated flowsheet in Figure 7 and conventional case in Figure 2, arabinoxylans now need to be sold at a price of 4352.86, 4882.8 and $5552.66 \mathrm{f} / \mathrm{t}$ respectively compared to $2355 \mathrm{f} / \mathrm{t}$ previously obtained without the consideration of CAPEX, as illustrated in Table 5 . Hence, the estimated AX market price based on overall considerations of plant operating and investment costs, is above $6 \mathrm{f} / \mathrm{kg}$. It can be noted that oil refineries operate with a plant life much higher than 5 years (Sadhukhan and Zhu, 2002). Plant life indicates the time within which no major investment occurs. Considering that biorefinery market is yet to establish against oil refinery, a shorter plant life is safer to work with. However, it's dependent upon the practitioner and market conditions and the methodology presented in this work can be conveniently adapted to different market scenarios. Furthermore, the capital cost analysis in Table 6 suggests that if a market can be created for $A X$ as a food ingredient with a selling price of $f 6 / k g$ (Basis: a plant life of 5 years, IRR $12 \%$ and annualized capital charge of $28 \%$ ), the ethanol coproduced can be sold at $10 \%$ less than from a conventional biorefinery (Figure 2) under current economic scenario. The analysis is presented in Table 6. Thus coproduction of $\mathrm{AX}$ appears to economically feasible and the additional revenue can allow a reduction in the selling price of ethanol.

Table 3

Table 4

Table 5 


\section{Summary}

Bioethanol production requires co-production in order to achieve viable commercial operation. The current study investigates into the production of arabinoxylans in the context of wheat based bioethanol production. This has the potential to enhance the economics of ethanol production. The work evaluated the likely production costs and market values of $A X$ if co-produced in a biorefinery principally producing bioethanol. The work also investigated into the potential of employing debranning technology within bioethanol production. Based on our combined computational and experimental study (Mustafa et al, 2007), presented in this paper the following recommendations and observations can be concluded.

1) Value Analysis is a powerful tool for assessment and selection of processing routes and products, which can be adopted for efficient design and operation of cereal biorefineries.

2) A detailed and comprehensive value analysis that includes capital investment policy has been presented. It indicates that the required market price for $A X$ to breakeven against conventional biorefineries without value added production is a strong function of plant life and this may vary between $4-6 f / k g$ for a plant life of 5 to 2 years respectively. Further it shows that if a market can be created for $A X$ as a food ingredient with a selling price of $6 \mathrm{f} / \mathrm{kg}$, the ethanol co-produced can be sold at $10 \%$ less than from a conventional biorefinery under current economic scenario.

3) AX suitable for food use can be extracted from wheat bran using alkaline hydrogen peroxide, with ethanol used for bran washing and AX precipitation, and the extract purified with enzymatic treatments.

4) Starch in bran can be recovered for ethanol production by washing the bran with water prior to extraction, and sending the water plus starch to the liquefaction stage.

5) After wheat, the major raw materials costs for ethanol production are the enzymes, while the major raw materials cost for AX extraction is the hydrogen peroxide. 
6) After raw materials, utilities comprise the next major operating cost, with steam making the largest contribution. The addition of AX extraction increases steam usage due to the additional distillation requirement of the recycled ethanol.

7) Superstructure of integrated flowsheets has also been provided for further investigation into various processing options.

8) Rigorous simulation results show promising results detailed elsewhere (Mustafa et al, 2007)

\section{Nomenclature}

Sets

$\mathrm{UNIT}=\{\mathrm{i} /$ process units $\}$

DS_UNIT $=\{d(i \in U N I T) /$ downstream process units of process unit $i\}$

US_UNIT $=\{\mathrm{U}(\mathrm{i} \in \mathrm{UNIT}) /$ upstream process units of process unit $\mathrm{i}\}$

$E D=\left\{e^{\prime}(i \in U N I T) /\right.$ downstream elements of process unit $\left.i\right\}$

$E U=\{e(i \in U N I T) /$ upstream elements to process unit $i\}$

$N P=\{q(i \in U N I T) /$ end products from process unit $i\}$

Variables

$\Delta \quad$ economic margin of a process unit

$\Delta_{i}\left(F_{e-i}\right) \quad$ marginal contribution of process unit $i$ as a function of feed to unit i

$\Delta_{d}\left(F_{e-i}\right) \quad$ marginal contribution of downstream process unit $d \in D_{-}$UNIT(i) of unit $i$ as a function of feed to unit $\mathrm{i}$

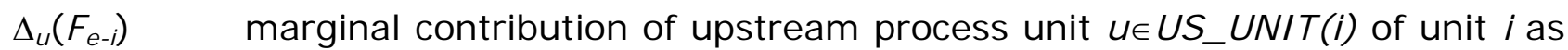
a function of feed to unit $i$

$\left(\mathrm{F}_{\mathrm{e}-\mathrm{i}}\right)_{\text {Cop }} \quad$ cost of production of feed $\mathrm{F}_{\mathrm{e}-\mathrm{i}}$ to unit $\mathrm{i}$ from upstream element $\mathrm{e} \in \mathrm{EU}(\mathrm{i})$

$\left(F_{e-i-e^{\prime}}\right)_{C O P} \quad c o s t$ of production of feed $F_{e-i-e^{\prime}}$ to downstream element $e^{\prime} \in E D(i)$ from unit $\mathrm{i} /$ element $\mathrm{e}-\mathrm{i}$

$(\mathrm{F})_{\mathrm{MP}} \quad$ spot on market price of feed to a process unit

$(F)_{\text {Vop }} \quad$ value on processing of feed to a process unit

$\left(F_{e-i}\right)_{\text {Vop }} \quad$ value on processing of feed $F_{e-i}$ to unit $i$ from upstream element $e \in E U(i)$ 
$\left(F_{e-i-e^{\prime}}\right)_{\text {VoP }} \quad$ value on processing of feed $F_{e-i-e^{\prime}}$ to downstream element $e^{\prime} \in E D(i)$ from unit i / element e-i

$(\mathrm{P})_{\mathrm{COP}} \quad$ cost of production of product from a process unit

$\left(P_{e-i, q}\right)_{\text {COP }} \quad$ cost of production of end product $P_{e-i, q}$ from element $e-i$

$(\mathrm{P})_{\mathrm{MP}} \quad$ spot on market price of product from a process unit

$\left(P_{e-i, q}\right)_{M P} \quad$ spot on market price of end product $P_{e-i, q}$ from element $e-i$

$\mathrm{m}^{\mathrm{F}} \quad$ flowrate of feed to a process unit

$m_{e-i}^{F} \quad$ flowrate of feed $F_{e-i}$ to unit i from upstream element $e \in E U(i)$

$m_{e-i-e^{\prime}}^{F} \quad$ flowrate of feed $F_{\text {e-i-e' }}$ to downstream element $e^{\prime} \in \operatorname{ED}(\mathrm{i})$ from unit $\mathrm{i} /$ element e-i

$m^{P} \quad$ flowrate of product from a process unit

$m_{e-i, q}^{P} \quad$ flowrate of end product $\mathrm{P}_{\mathrm{e}-\mathrm{i}, \mathrm{q}}$ from element e-i

$\hat{o}_{\mathrm{i}} \quad$ operating cost of process unit i per unit flowrate in terms of feed flow distributions and product yields

$\mathrm{O} \quad$ total operating cost of a unit

$\mathrm{O}_{\mathrm{i}} \quad$ total operating cost of a unit $\mathrm{i}$

\section{Acknowledgements}

The authors gratefully acknowledge the financial support of Home-Grown Cereals Authority (HGCA) of the UK for undertaking this research (RD-2005-3186).

The authors also gratefully acknowledge assistance of Malcolm Shepherd and Mike Branch (Green Spirit Fuel Ltd.), Andy Bailey and Martin Clare (Satake Corporation UK Division), Dr Mairi Black (HGCA) in undertaking this research. Dr Richard Weightman (ADAS) is also gratefully acknowledged for numerous helpful comments.

\section{Appendix A. Conventional bioethanol production}

The utility consumptions and yields of processes, price of streams and compositions of wheat and bran that are used as the basis for this work are presented in Tables A1-A5 respectively. The calculations are based on $340 \mathrm{kt} / \mathrm{y}$ of wheat processing and 330 days of operation per year.

Table A1: Utility consumptions of various process units in a starch processing facility 


\begin{tabular}{|c|c|c|c|c|c|c|c|c|}
\hline \multirow[t]{2}{*}{ Process unit } & \multicolumn{8}{|c|}{ Utilities } \\
\hline & $\begin{array}{c}\text { Process } \\
\text { water } \\
\text { (v/w) }\end{array}$ & $\begin{array}{c}\text { Electricity } \\
(\mathrm{KW})\end{array}$ & $\begin{array}{c}\text { Electricity } \\
(\mathrm{KW})\end{array}$ & Steam (t/h) & Steam (t/h) & $\begin{array}{l}\text { Natural } \\
\text { gas }(\mathrm{t} / \mathrm{h})\end{array}$ & $\begin{array}{l}\text { Cooling water } \\
\text { (t/h) }\end{array}$ & $\begin{array}{c}\text { Cooling water } \\
(\mathbf{t} / \mathbf{h})\end{array}$ \\
\hline Milling & - & - & 1200 & - & - & - & - & - \\
\hline Liquefaction & 1.84 & 89 & 76.34 & 10.63 & 9.12 & - & - & - \\
\hline Saccharification & - & 29.8 & 25.56 & - & - & - & 121.93 & 104.59 \\
\hline Fermenter & - & 159.1 & 136.48 & - & - & - & 417.07 & 357.76 \\
\hline Centrifugation & - & 331.8 & 284.62 & - & - & - & - & - \\
\hline Ethanol recovery & - & 51 & 43.75 & 25 & 21.60 & - & 631.31 & 631.31 \\
\hline Rotary Dryer & - & 331.8 & 284.62 & - & - & 0.75 & - & - \\
\hline $\mathrm{CO}_{2}$ Recovery & - & 1167 & 1355 & - & - & - & - & - \\
\hline
\end{tabular}

Table A2. Recovery from various process units in a starch processing facility

\begin{tabular}{|l|c|}
\hline \multicolumn{1}{|c|}{ Process units } & Recovery \\
\hline Milling (Hammer) & 1 \\
\hline Liquefaction & 0.98 \\
\hline Saccharification & 0.97 \\
\hline Fermenter & 0.46 \\
\hline Centrifugation & 0.8 \\
\hline Ethanol recovery & 0.98 \\
\hline Washing & 0.98 \\
\hline Treatment & 0.95 \\
\hline Sieving \& washing & 0.98 \\
\hline Precipitation & 0.95 \\
\hline Ultrafiltration & 0.9 \\
\hline Centrifugation 2 & 0.8 \\
\hline Rotary dryers & 0.95 \\
\hline CO2 recovery & 0.9 \\
\hline
\end{tabular}

Table A3: Cost of raw materials, products, and utilities

\begin{tabular}{lll}
\hline Streams & & Price \\
Products & Ethanol & $590 \mathrm{f} / \mathrm{t}$ \\
& DDGS & $65-80 \mathrm{f} / \mathrm{t}$ \\
& $\mathrm{CO}_{2}$ & $10.7 \mathrm{f} / \mathrm{t}$ \\
& All waste stream & $0 \mathrm{f} / \mathrm{t}$ \\
Raw materials & \\
& Wheat & $96 \mathrm{f} / \mathrm{t}$ \\
& All enzymes & $2000 \mathrm{f} / \mathrm{t}$ \\
& Yeast & $6.67 \mathrm{f} / \mathrm{t}$ \\
\hline
\end{tabular}




\begin{tabular}{|c|c|c|}
\hline & $\mathrm{CaCl}_{2}$ & $130 \mathrm{f} / \mathrm{t}$ \\
\hline & Hydrogen peroxide ( $2 \%)$ & $500 f / t$ \\
\hline & Sodium hydroxide (25\%) & $1600 \mathrm{f} / \mathrm{t}$ \\
\hline & Conc. Sulphuric acid & $40 f / t$ \\
\hline \multirow[t]{6}{*}{ Cost of Utilities } & Electricity & $0.012 f / M J$ \\
\hline & Cooling water (cooling towers): & $0.015 \mathrm{f} / \mathrm{t}$ \\
\hline & Steam (from direct fired boilers) & $7 \mathrm{f} / \mathrm{t}$ \\
\hline & Refrigeration $\left(0^{\circ} \mathrm{C}\right)$ : & $0.006 f / M J$ \\
\hline & Mains water (process water) & $0.6 \mathrm{f} / \mathrm{t}$ \\
\hline & Natural gas & $4 f /$ million Btu \\
\hline
\end{tabular}

Table A4: Wheat composition

\begin{tabular}{cc}
\hline Components & Composition (\% dry basis) \\
Starch & 69 \\
Sugar & 3 \\
Protein & 11.5 \\
Non-starch polysaccharides & 11 \\
Lipid & 2.5 \\
Ash & 2 \\
Lignin & 1 \\
\hline
\end{tabular}

Table A5: The composition of wheat bran from various processing options

\begin{tabular}{|l|c|c|c|c|}
\hline \multirow{2}{*}{ Compositions } & \multicolumn{3}{|l|}{$\begin{array}{l}\text { Bran produced } \\
\text { with a debranner }\end{array}$} & \multicolumn{2}{l|}{$\begin{array}{l}\text { R Roller Mill from } \\
\text { a debranned wheat }\end{array}$} \\
\cline { 2 - 5 } & $4 \%$ & $8 \%$ & $4 \%$ & $8 \%$ \\
\hline Protein (\%, dry basis) & 6.8 & 11.8 & 19.3 & 23.4 \\
\hline Starch (\%, dry basis) & 17.6 & 26.9 & 21.9 & 21.8 \\
\hline Glucose (\%, dry basis) & 3.1 & 3.4 & 3.7 & 3.2 \\
\hline Arabinoxylan (\%, dry basis) & 26.8 & 18.6 & 17.2 & 15.8 \\
\hline Others (\%, dry basis) & 45.7 & 39.3 & 37.9 & 35.8 \\
\hline
\end{tabular}


A general description of the conventional wheat based bioethanol flowsheet in Figure 2 is as follows. The bulk of global production of ethanol comes from agricultural alcohol which may be distilled from a number of sources such as grain, molasses, fruit, wine, and cellulose. Roughly $60 \%$ of the world's ethanol production is from sugar crops (Berg, 2003). Most of the remainder comes from grain, predominantly from maize, but with wheat becoming increasingly attractive as an alternative feedstock to maize in areas where wheat dominates, such as Canada. In the UK and EU wheat poses the cereal of choice.

The conventional production of ethanol from grain goes through a number of stages to produce ethanol. The key operations are milling (Ladisch et al, 1991; Kwiatkowski et al, 2006; Maes and Delcour, 2001), starch hydrolysis (Lin and Tanaka, 2006; Warren et al, 1994), fermentation (Berg, 2003), centrifugation (Keim and Venkatasubramanian, 1989), ethanol recovery (Warren et al, 1994) and DDGS production (McAloon et al, 2000). Recently, a new wheat milling technology, pearling (or debranning) has been commercialized. Adapted from rice milling, this approach uses friction and abrasion to partially remove the outer layers of the wheat kernel. Starch hydrolysis is a mature technology that utilises enzymatic liquefaction and saccharification to produce a relatively clean glucose stream, which is then fermented by yeast to produce ethanol. Distillers Dried Grains with Solubles (DDGS) and $\mathrm{CO}_{2}$ are the main by-products.

\section{Appendix B. Integrated ethanol and AX production flowsheet options}

Figure B1 shows a superstructure containing all possible connections and raw material requirements by unit operations within the superstructure. Also, the utility requirements by the various unit operations are presented in Figure B2. Figure B3 depicts ethanol reuse options for recovering $A X$ in different stages, in particular ethanol concentration requirements by the various stages in AX recovery. $96 \%$ ethanol, from the ethanol recovery stage, is fed into the Precipitation and the Washing (2) steps. The ethanol is then recovered from the waste stream from Centrifugation (2) and Washing (2). This combined stream is then topped up with ethanol from the ethanol recovery stage to meet the requirements for Treatment (1) and Sieving and Washing (1). The waste streams from those 2 units are then sent back to the ethanol recovery stage. 


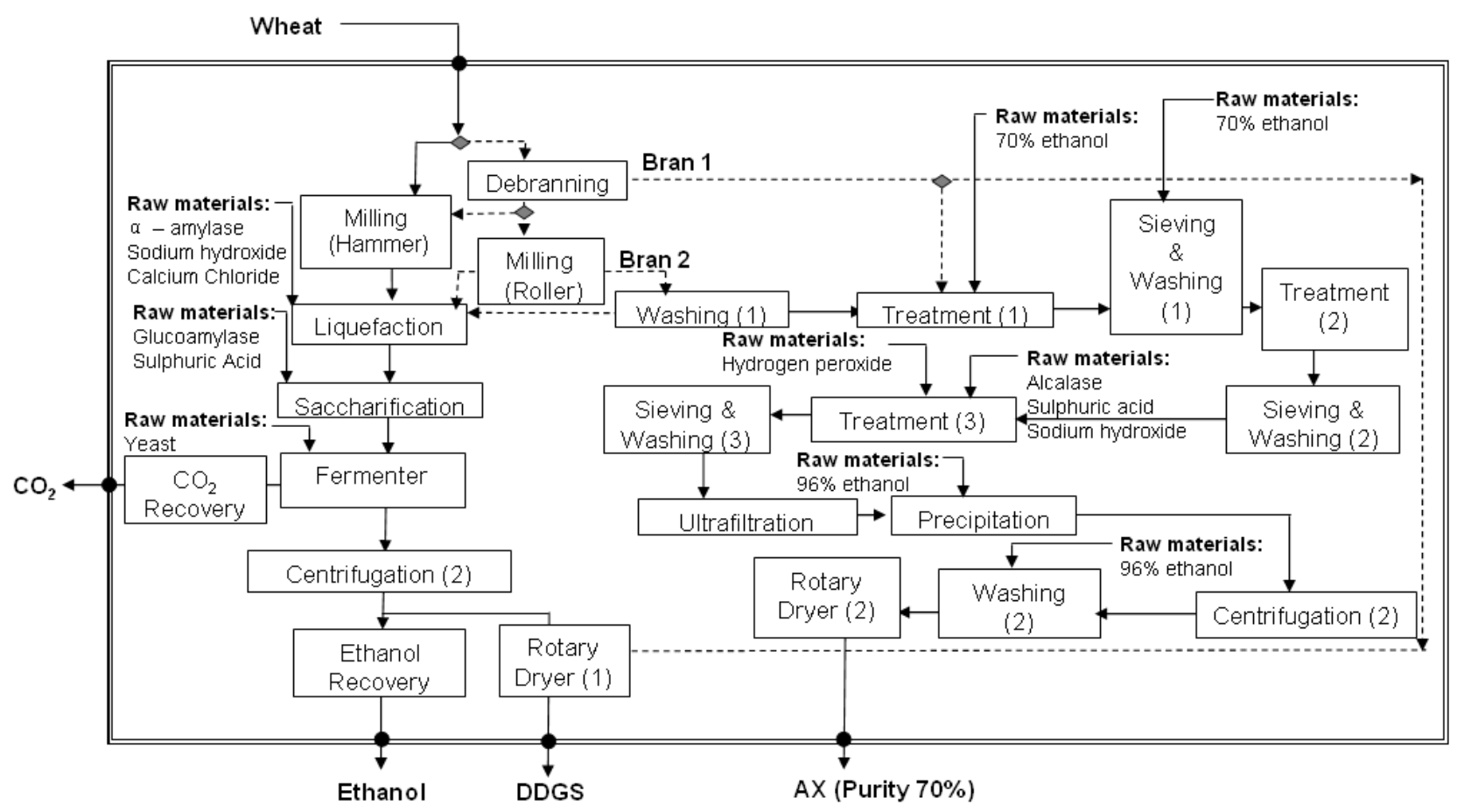

Figure B1. Raw material requirements by the unit operations in the integrated ethanol and AX flowsheet superstructure

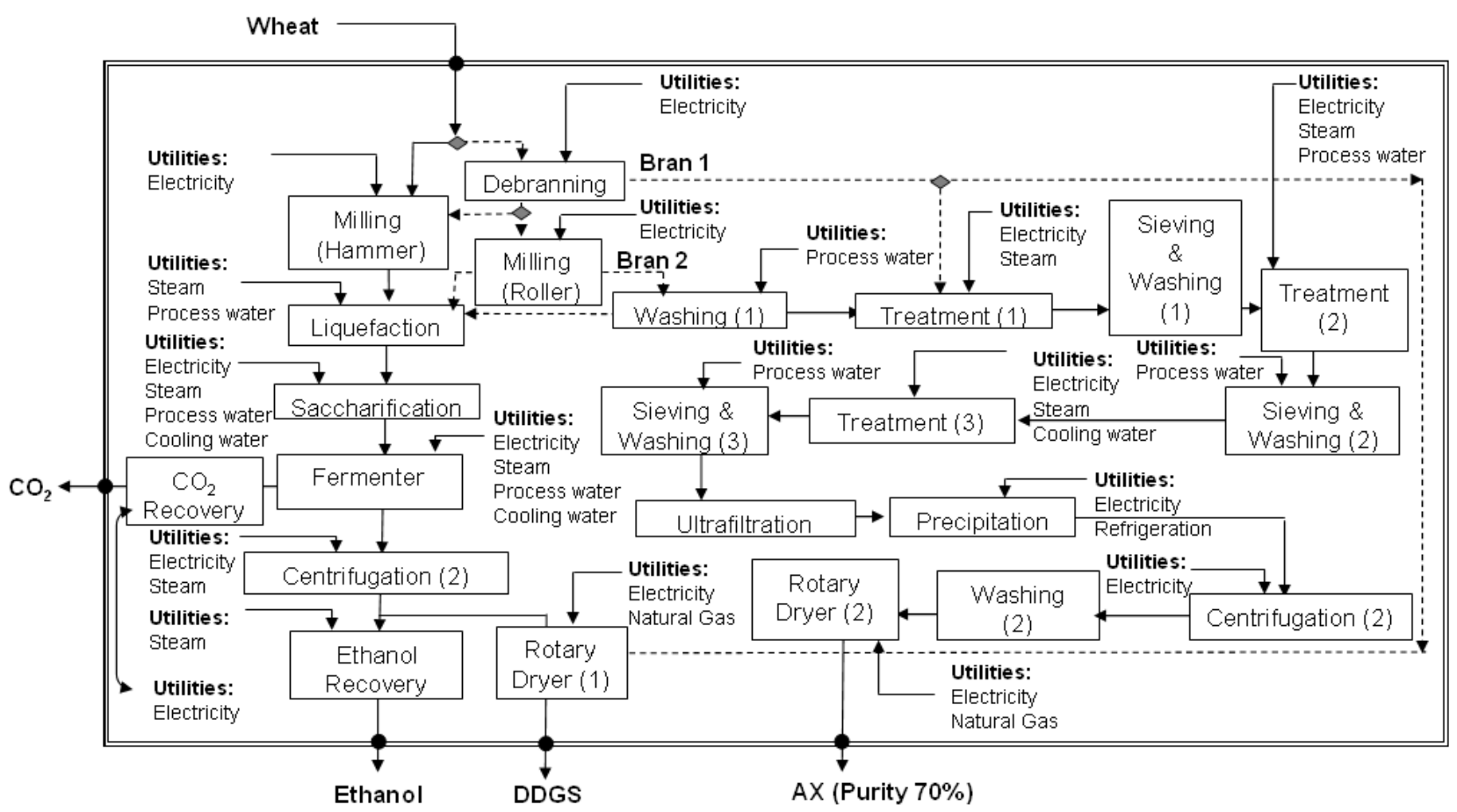

Figure B2. Utility requirements by the unit operations in the integrated ethanol and AX flowsheet superstructure 


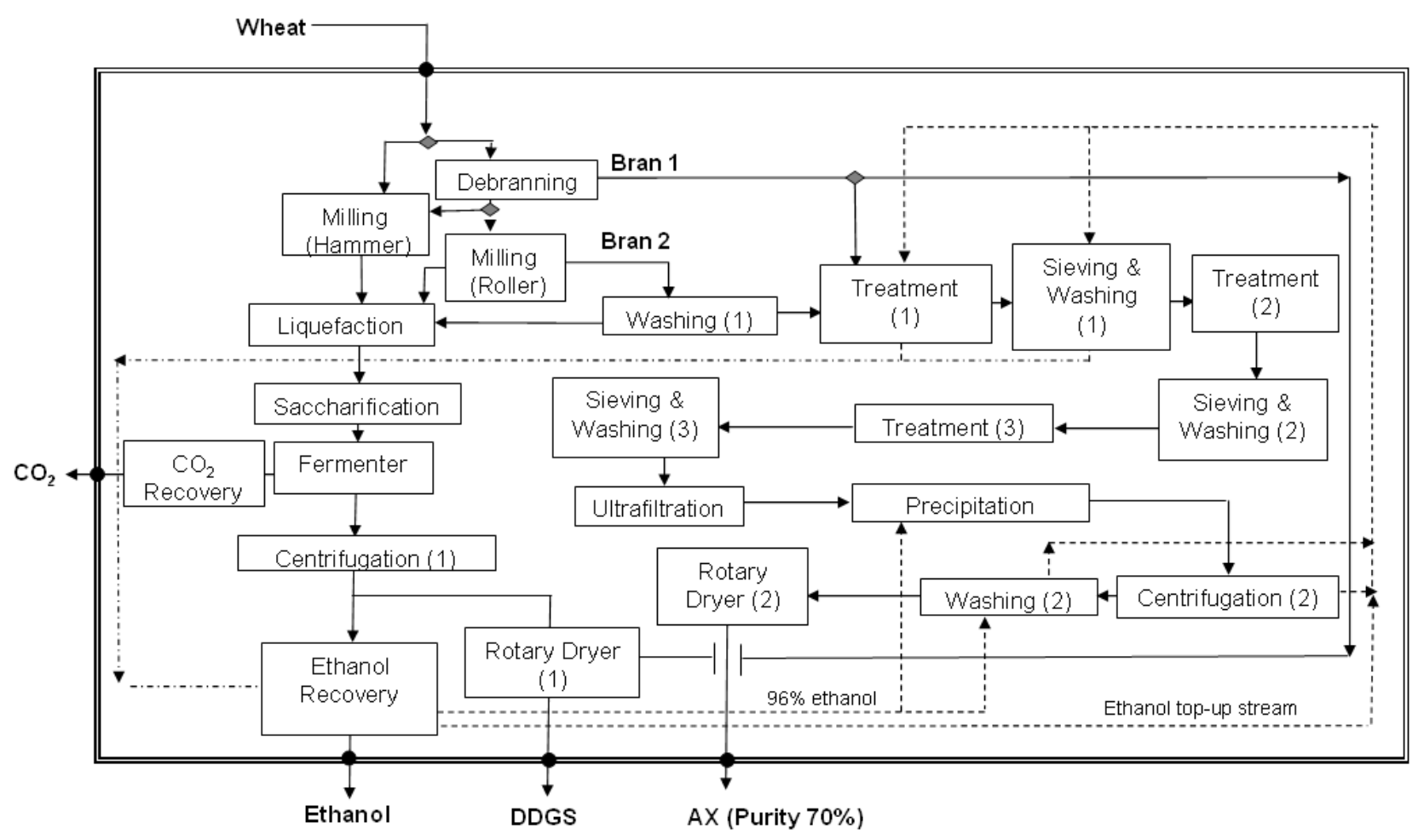

Figure B3. Ethanol reuse by the various $A X$ recovery stages

\section{References}

1. Sadhukhan, J., Zhang, N. and Zhu, X. X. (Frank), 2003, Value analysis of complex systems and industrial application to refineries, Industrial \& Engineering Chemistry Research, 42(21), 5165.

2. Sadhukhan, J., Zhang, N. and Zhu, X. X. (Frank), 2004, Analytical optimisation of industrial systems and applications to refineries, petrochemicals', Chemical Engineering Science, 59(20), 4169.

3. Sadhukhan, J. and Smith, R., 2007, Synthesis of industrial systems based on value analysis, Computers \& Chemical Engineering, 31(5-6), 535.

4. USDA Foreign Agricultural Service, Global Agricultural Information Network report no: RP7029, 2007, Philippines bio-fuels annual 2007. 
5. Koutinas, A. A., Wang, R., Campbell, G. M. and Webb, C., 2006, A whole crop biorefinery system: A closed system the manufacture of non-food products from cereals, Whole Crop Biorefinery, 8, 165.

6. Campbell, G. M., Koutinas, A. A., Wang, R-H., Sadhukhan, J. and Webb, C., 2006, Cereal Potential, The Chemical Engineer, 781, 26.

7. Bergmans, M. E. F., Beldman, G., Gruppen, H., and Voragen, A. G. J., 1996, Optimisation of the selective extraction of (Glucurono)arabinoxylans from wheat Bran: Use of barium and calcium hydroxide solution at elevated temperatures, Journal of Cereal Science, 23, 235.

8. Bergmans, M. E. F., van Dijk, J. M., Beldman, G. and Voragen, A.G.J., 1999, Physicochemical characteristics of wheat bran glucuronoarabinoxylans, Journal of Cereal Science, 29, 49.

9. Courtin, C. and Delcour, A., 2002, Arabinoxylans and endoxylanase in wheat flour bread-making, Journal of Cereal Science, 35, 225.

10. Grootaert, C., Delcour, J., Courtin, C., Broekaert, W., Verstraete, W. and Van de Wiele, T., 2007, Microbial metabolism and prebiotic potency of arabinoxylan oligosaccharides in the human intestine, Trends in Food Science and Technology, 18, 64.

11. Miraftab, M., Qiao, Q., Kennedy, J. F., Anand, S. C., and Groocock, M. R., 2003, Fibres for wound dressings based on mixed carbohydrate polymer fibres, Carbohydrate Polymers, 53, 225.

12. Peroval, C., Debeaufort, F., Seuvre, A.-M., Cayot, P., Chevet, B., Despré, D. and Voilley, A., 2004, Modified arabinoxylan-based films: Grafting of functional acrylates by oxygen plasma and electron beam irradiation, Journal of Membrane Science, 233, 129.

13. Mah, R. S. H., 1983, Application of graph theory to process design and analysis, Computers and Chemical Engineering, 7, 239. 
14. Sadhukhan, J. 2005, Analytical optimisation of industrial systems based on economic analysis, 7th World Congress of Chemical Engineering, Glasgow, Scotland, 10- 14 J uly.

15. Sadhukhan, J., 2002, A novel value analysis method for process network optimisation, PhD Dissertation, UMIST, Manchester, UK.

16. Smith, T. C., Kindred, D. R., Brosnan, J. M., Weightman, R., M., Shepherd, M., and Sylvester-Bradley, R., 2006, Wheat as a feedstock for alcohol production, HomeGrown Cereal Authority Research Review No. 61.

17. Sinnott, R. K., 2003, Coulson \& Richardson's Chemical Engineering - Design (vol 6). Butterworth and Heinemann, Oxford.

18. Sadhukhan, J. and Campbell, G. M., 2005, Integrated exploitation of wheat for non-food products: An integration and assessment framework, Home-Grown Cereals Authority of the UK funded research: RD-2005-3186.

19. Batchelor, S. E., Cook, P., Booth, E. J. and Walker, K. C., 1994, Economics of bioethanol production from wheat in the UK, Renewable Energy, 5, 807.

20. Bataillon, M., Mathaly, P., Nunes, Cardinali, A. P. and Duchiron, F., 1998, Extraction and purification of arabinoxylan from destarched wheat bran in a pilot scale, Industrial Crops and Products, 8, 37.

21. Maes, C. and Delcour, J. A., 2001, Alkaline hydrogen peroxide extraction of wheat bran non-starch polysaccharides, Journal of Cereal Science, 34, 29.

22. Weightman, R. M., Fitchett, C. S. and Greenshields, R., 2002, Improvements relating to bran gels, Patent No: US $6482430 \mathrm{B1}$.

23. Hollman, J. and Lindhauer, M. G., 2005, Pilot-scale isolation of glucuronoarabinoxylans from wheat bran, Carbohydrate Polymers, 59, 225.

24. Mustafa, M. A., Misailidis, N., Mateos-Salvador, F., Du, C., Sadhukhan, J. and Campbell, G. M., 2007, Integrated exploitation of wheat for non-food products: An 
integration and assessment framework, Report submitted to Home-Grown Cereals Authority of the UK: RD-2005-3186.

25. Kwiatkowski, J. R., McAloon, A. J., Taylor, F. and Johnston, D. B., 2006, Modelling the process and cost of fuel ethanol production by the corn dry-grind process, Industrial Crops and Products, 23, 288.

26. Hamelinck, C. N., Suurs, R. A. A. and Faaij, A. P. C., 2005, International bioenergy transport costs and energy balance, Biomass and Bioenergy, 29(2), 114.

27. Sadhukhan, J. and Zhu, X. X. (Frank), 2002, Integration strategy of gasification technology: a gateway to the future refining, Industrial \& Engineering Chemistry Research, 41(6), 1528.

28. Berg, C., 2003, World bioethanol production, Bioenergy Review, 1, 5.

29. Ladisch, M. R. and Svarczkopf, J. A., 1991, Ethanol production and the cost of fermentable sugars from biomass, Bioresource Technology, 36, 83.

30. Lin, Y. and Tanaka, S., 2006, Ethanol fermentation from biomass resources: current state and prospects, Applied Microbiology Biotechnology, 69, 627.

31. Warren, R. K, Macdonald, D. G. and Hill, G. A., 1994, The design and costing of a continuous ethanol process using wheat and cell recycle fermentation. Bioresource Technology, 47, 121.

32. Keim, C. R. and Venkatasubramanian K., 1989, Economics of current biotechnological methods of producing ethanol, Trends in Biotechnology, 7, 2, 22.

33. McAloon, A., Taylor, F., Yee, W., Ibsen, K. and Wooley, R., 2000, Determining the cost of producing ethanol from corn starch and lignocellulosic feedstocks. Technical Report. A Joint Study Sponsored by: U.S. Department of Agriculture and U.S. Department of Energy. National Renewable Energy Laboratory. NREL/TP-580-28893. 